\title{
Easy Epoxidation of Monoterpenes from Common Starting Materials
}

\author{
John H. Bermudez, ${ }^{a}$ Giovanni Rojas, ${ }^{\oplus *, b}$ Ricardo B. Benitez $z^{a}$ and Jaime M. Franco ${ }^{\oplus *, a}$ \\ ${ }^{a}$ Grupo de Investigación Química de Productos Naturales (QPN), Departamento de Química, \\ Universidad del Cauca, Calle 5 No. 4-70, Popayán, Colombia \\ ${ }^{b}$ Departamento de Ciencias Químicas, Facultad de Ciencias Naturales, Universidad Icesi, \\ Calle 18 No. 122-135, Cali, Colombia
}

\begin{abstract}
Epoxidation of monoterpenes, $\alpha$-pinene, $\beta$-pinene, limonene, $\alpha$-terpinene, and $(R)$-carvone was carried out by the in situ production of a peroxyacid rather than direct addition of such an expensive and difficult to handle chemical. Previous reports showed use of metal catalysts with high yields, while methodologies without catalysts at high temperature showed yields lower than $30 \%$. The authors report a methodology that produces peroxyacetic acid in situ yielding up to $75 \%$ pure epoxide at room temperature avoiding the use of catalysts. The products were analyzed by gas chromatography mass spectrometry (GC-MS), and structures were characterized by ${ }^{1} \mathrm{H}$ and ${ }^{13} \mathrm{C}$ nuclear magnetic resonance (NMR).
\end{abstract}

Keywords: epoxidation, pinene, limonene, terpinene, carvone peroxyacetic acid

\section{Introduction}

Epoxidation of olefins is important for industrial processes, because epoxides are easily converted into diverse products or functional groups. They are present in natural sources, such as leaves, flowers and bark. ${ }^{1-3}$ Epoxides are frequently used in the perfume industry as starting materials or intermediates of fragrances, ${ }^{1}$ which are complex mixtures that are normally composed of secondary metabolites like terpenoid structures, for example limonene, $\alpha$ - and $\beta$-pinene, among others. ${ }^{4}$ Essential oils also find application as solvents, production of lacquer, fibers like rayon, cosmetics, cleaning products and in the food industry. ${ }^{5}$ Epoxides from fragrances are especially important because they are easily converted into glycols, amino alcohols, and esters. ${ }^{6-9}$

The synthesis of epoxides requires addition of expensive, unstable and hard to handle oxidizing reagents, normally involving an excess of peroxyacetic acid (PAA), 3-chloroperbenzoic acid (mCPBA), hydroperoxides, and dimethyldioxirane (DMDO). ${ }^{10,11}$ Hydrogen peroxide is a convenient oxygen donor, but it requires the use of a metal catalyst. For example, tungsten, manganese, iron, and chromium catalyze epoxidation of olefins in high yields. ${ }^{12,13}$ Palladium and gold catalysts are used

*e-mail: grojas@icesi.edu.co; jmartinf@unicauca.edu.co in combination with hydrogen peroxide for improving stereoselectivity. ${ }^{14}$ Although homogeneous catalytic systems can become problematic during product isolation, heterogeneous catalysts such as oxide mixtures, zeolites, ${ }^{15-17}$ and supported metals are good options for easy epoxide final purification. ${ }^{18}$ The Juliá-Colonna epoxidation employs phase transfer catalysis for the asymmetric epoxidation of chalcones with high enantiomeric excess of the product. ${ }^{19}$ Normally the addition of peroxyacetic acid yields about $30 \%$ of the respective epoxide. ${ }^{20}$ We now report the easy and economical in situ production of the peroxyacid from tetraacetylethylenediamine (TAED) and sodium percarbonate (SPC) with yields up to $75 \%$ without using any metal catalyst at room temperature, for the epoxidation of monoterpenes.

Figure 1 shows the chemical structures of TAED and SPC, both of which are economical and easy to handle chemicals. SPC is commonly known as sodium peroxycarbonate or solid hydrogen, which is used as a bleach in laundry detergents, because it easily forms hydrogen peroxide once it reacts with water. TAED has been reported as a bleaching activator after reacting with $\mathrm{SPC}$ in an aqueous medium forming peroxyacetic acid.

\section{Experimental}

Preliminary studies were performed with chemicals 
<smiles>CC(=O)N(CCN(C(C)=O)C(C)=O)C(C)=O</smiles>

TAED

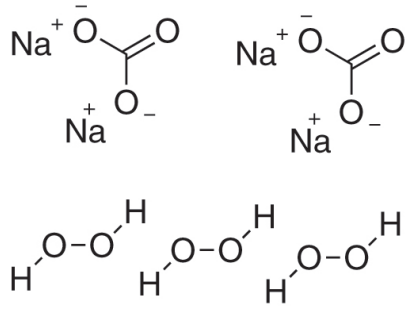

SPC

Figure 1. Chemical structures of TAED and SPC.

donated by Garcia and Millán Company (Cali, Colombia), which commercializes chemicals for bleaching and disinfection. Once the preliminary studies were successful, TAED, SPC and monoterpenes were purchased from Merck (Cali, Colombia), and they were used without any further purification. The following method for epoxidation of monoterpenes was optimized by changing parameters such as reaction time, solvent, temperature and molar ratio. Epoxidation of $\alpha$-pinene using the best experimental conditions is shown as described below, and this is the general method used for the epoxidation of all substrates, from 1 to 8 in Table 1.

Synthesis of the epoxide from $\alpha$-pinene with TAED and SPC

In a $50 \mathrm{~mL}$ round bottom flask with magnetic stirring bar that contained $136.2 \mathrm{mg}$ (1.0 mmol, 1.00 equivalent) of $\alpha$-pinene and $12.5 \mathrm{~mL}$ of dichloromethane (DCM), it was added $252 \mathrm{mg}$ ( $3.0 \mathrm{mmol}, 3.0$ equivalents) of sodium bicarbonate, $414 \mathrm{mg}$ ( $3 \mathrm{mmol}, 3$ equivalents) of SPC and $342.4 \mathrm{mg}$ ( $1.5 \mathrm{mmol}, 1.5$ equivalents) of TAED. The round bottom flask was capped and left under vigorous stirring at room temperature. The progress of the reaction was monitored by thin layer chromatography (TLC) from the first hour. After $3 \mathrm{~h}$ of reaction, the organic and aqueous layers were separated, and extraction of the aqueous layer was carried out three times with $10 \mathrm{~mL}$ of DCM. The combined organic layers were washed with $40 \mathrm{~mL}$ of water and $40 \mathrm{~mL}$ of brine. The obtained organic layer was dried with sodium sulfate obtaining a crude product. The mobile phase used for TLC was ethyl acetate and petroleum ether $15 \% \mathrm{v} / \mathrm{v}$ and the chromatography plate was developed with an ethanolic solution of phosphomolybdic acid.

Purification by flash chromatography eluting with 5\% ethyl acetate/petroleum ether yielded in all cases more than $75 \%$ pure epoxide. The following spectral properties were observed: ${ }^{1} \mathrm{H} \mathrm{NMR}\left(400 \mathrm{MHz}, \mathrm{CDCl}_{3}\right) \delta 0.93\left(\mathrm{~s}, 3 \mathrm{H}, \mathrm{CH}_{3}\right)$, $1.28\left(\mathrm{~s}, 3 \mathrm{H}, \mathrm{CH}_{3}\right), 1.33$ (s, 3H, $\left.\mathrm{CH}_{3}\right), 1.62(\mathrm{~d}, 2 \mathrm{H}, J 9.5 \mathrm{~Hz}$, $\left.\mathrm{CH}_{2}\right), 1.68-1.74(\mathrm{~m}, 1 \mathrm{H}, \mathrm{CH}), 1.85-2.03\left(\mathrm{~m}, 5 \mathrm{H}, \mathrm{CH}_{2}, \mathrm{CH}_{2}\right.$, $\mathrm{CH}), 3.04(\mathrm{~d}, 1 \mathrm{H}, J 3.9 \mathrm{~Hz}, \mathrm{CH}) ;{ }^{13} \mathrm{C}$ NMR $(100 \mathrm{MHz}$,
Table 1. Monoterpenes and their respective epoxides and reaction yields

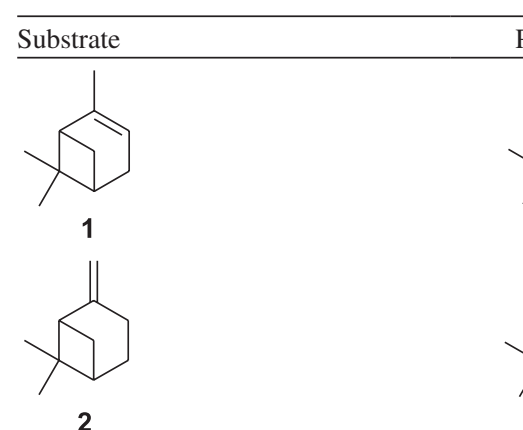<smiles>C1=CCCCC1</smiles><smiles>CC1(C)CCC2(CC3CCC2(C)C3)O1</smiles><smiles>CC1(C)C2CCCC1(C)C21CO1</smiles>

P2<smiles></smiles>

68

3

P3<smiles>C=C(C)C1CC=C(C)CC1</smiles><smiles>C=C(C)C1CCC2(C)OC2C1</smiles>

4

P4<smiles>CC1=CC=C(C(C)C)CC1</smiles><smiles>CC(C)C12CCC3(C)OC3C1O2</smiles>

P5

5<smiles>C=C1CCCC2OC12C</smiles><smiles>C=C(C)[C@H]1CC=C(C)C(=O)C1</smiles><smiles>C=C(C)C</smiles>

P6<smiles>O=C(C/C=C/c1ccccc1)C/C=C/c1ccccc1</smiles>

N.P.

N.P.<smiles>O=C(O)/C=C/c1ccccc1</smiles>

N.P.: no epoxidation product was observed. 
$\left.\mathrm{CDCl}_{3}\right) \delta 60.20,56.82,45.13,40.50,39.78,27.63,26.70$, 25.84, 22.37, 20.14; high-resolution mass spectrometry (HRMS) (electron ionization (EI)) $\mathrm{m} / \mathrm{z}$, calculated for $\mathrm{C}_{10} \mathrm{H}_{16} \mathrm{O}[\mathrm{M}]^{+}:$152.1201, found: 152.1198. Elemental analysis calculated for $\mathrm{C}_{10} \mathrm{H}_{16} \mathrm{O}: \mathrm{C}, 78.90 ; \mathrm{H}, 10.59$; O, 10.51; found: C, 78.91; H, 10.60; O, 10.51 .

\section{Gas chromatography coupled to a mass detector (GC-MS)}

A Shimadzu GCMS-QP-2010 was employed for separation of products and starting materials. The column was a Restek XTI-5. The following heating ramps were carried out: (i) initial temperature of $40{ }^{\circ} \mathrm{C}$ for $1 \mathrm{~min}$, (ii) heating at $5{ }^{\circ} \mathrm{C} \mathrm{min}^{-1}$ up to $200{ }^{\circ} \mathrm{C}$, (iii) heating at $10{ }^{\circ} \mathrm{C} \mathrm{min}-1$ up to $300{ }^{\circ} \mathrm{C}$. The mass spectrometer transfer line was maintained at $350{ }^{\circ} \mathrm{C}$, and the potential of the ionization source (EI) was $70 \mathrm{eV}$. Mass spectra were repeatedly scanned from $m / z$ 30-250. The acquired mass spectrum was matched with the mass spectrum in the Shimadzu GCMS-QP-2010 local library.

\section{Analysis by nuclear magnetic resonance (NMR)}

NMR analyses of pure products were carried out in a Bruker instrument at $400 \mathrm{MHz}$ for ${ }^{1} \mathrm{H}$ and $100 \mathrm{MHz}$ for ${ }^{13} \mathrm{C}$. All ${ }^{1} \mathrm{H}$ and ${ }^{13} \mathrm{C}$ NMR spectra were recorded in $\mathrm{CDCl}_{3}$. Chemical shifts were referenced to residual signals from $\mathrm{CDCl}_{3}$ (7.27 ppm for ${ }^{1} \mathrm{H}, 77.23$ ppm for ${ }^{13} \mathrm{C}$ ) with $0.03 \% \mathrm{v} / \mathrm{v}$ tetramethylsilane (TMS) as an internal reference. The NMR splitting patterns are designated as follows: s, singlet; $d$, doublet; $\mathrm{t}$, triplet; m, multiplet; br, broad signal.

\section{Results and Discussion}

In order to test our proposed methodology, it was necessary to reproduce the reaction previously reported by Furniss et $a l .{ }^{20}$ in which $\alpha$-pinene was epoxidized by the addition of peroxyacetic acid $(20 \% \mathrm{~m} / \mathrm{m})$ under constant stirring in a biphasic toluene/water solution at $40{ }^{\circ} \mathrm{C}$ during
$3 \mathrm{~h}$ of reaction. ${ }^{21}$ The reaction produced the expected epoxide, but even though an excess of peroxyacid was added during the course of the reaction, yields lower than 30\% were obtained in all cases. In contrast, when the reaction was performed by in situ production of peroxyacetic acid from TAED and SPC in a mixture of water/DCM, ${ }^{22}$ yields were improved dramatically, the epoxidation of monoterpenes yielded up to $75 \%$ pure epoxide. Although the following discussion is focused on the data obtained for the epoxidation of $\alpha$-pinene (1), information related to a series of monoterpenes and some model chemicals, from 2 to $\mathbf{8}$ in Table 1, showed similar results, which are available in the Supplementary Information (SI) section.

After one hour, the reaction progress for the epoxidation of $\alpha$-pinene was monitored by TLC, as the starting material began to disappear while the epoxide product, 2,7,7-trimethyl-3-oxatricyclo[4.1.1.0 $\left.0^{2,4}\right]$ octane (P1), appeared. ${ }^{22}$ Figure S1 (SI section) shows the TLC of the starting material and crude product. Although the mixture was reacted for periods longer than $3 \mathrm{~h}$, no effect on the reaction yield was observed; no by-products were produced and only epoxide and $\alpha$-pinene were recovered.

Scheme 1 shows the formation of peroxyacetic acid from TAED and SPC. While in previous reports PAA was added directly to the reaction, the in situ formation of PAA in the interphase of DCM and water for epoxidation has not been previously reported in the literature. In addition, it is important to note that the reaction produces two equivalents of PAA per every equivalent of TAED, improving the atom economy of the reaction.

Once the PAA is formed, it rapidly reacts with the unsaturation of the monoterpene, yielding the desired product epoxides (Scheme 2). Table 1 summarizes a series of monoterpenes, from $\mathbf{1}$ to $\mathbf{8}$, and their respective epoxidized products, from $\mathbf{P 1}$ to $\mathbf{P 6}$. It is important to highlight that cyclohexene (3), dibenzylideneacetone (7), and cinnamic acid $(\mathbf{8})$ were also included in the series of monoterpenes as model compounds. In addition, limonene showed to be regioselective for the annular epoxidation as

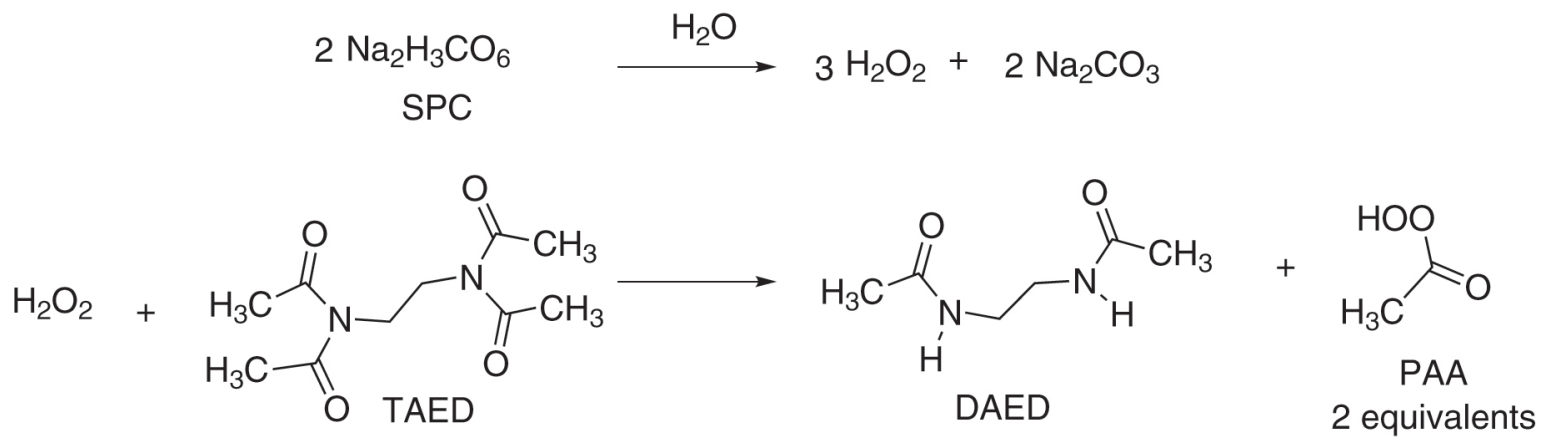

Scheme 1. Formation of peroxyacetic acid from SPC and TAED. 


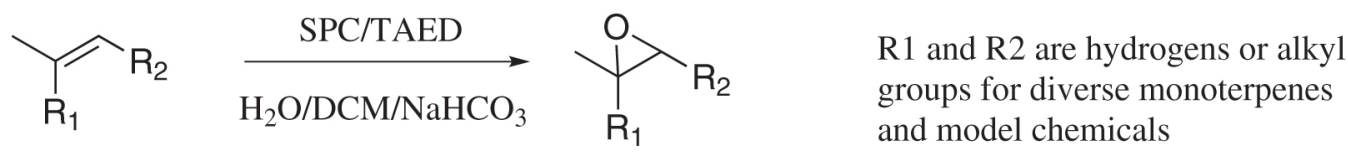

from (1) to (8)

from (P1) to (P6)

Scheme 2. General epoxidation of monoterpenes with PAA formed in situ.

shown in Table 1. Although no mechanistic studies were carried out during this investigation, probably a classical transition state is formed by a five-membered ring involving the peroxide oxygen from PAA and the unsaturation. ${ }^{23}$

Gas chromatography analysis (Figure 2) of the crude product showed two major compounds, which eluted at 6.49 and $9.35 \mathrm{~min}$, respectively. The peak at $6.49 \mathrm{~min}$ corresponds to $\alpha$-pinene, and the peak at 9.35 min belongs to the $\alpha$-pinene epoxide. Two more peaks were observed at 9.83 and $10.39 \mathrm{~min}$, which were small impurities or by-products from side reactions.

Both major components were further characterized by detailed mass spectrometry analysis and comparison of the fragmentation pattern with spectra in the instrument library. Figure 3 shows the mass spectrum of the chromatographic peak with retention time of $6.49 \mathrm{~min}$, which corresponds to $\alpha$-pinene. As expected, the molecular ion of $\alpha$-pinene shows a signal at $m / z 136$ with a base peak at $m / z 93$. Since a hard ionization technique (EI) was used, the signal of the molecular ion shows low abundance.

Figure 4 shows the mass spectrum of the component with retention time of $9.35 \mathrm{~min}$, which displays a base peak of $m / z 67$. Structural characterization by NMR showed that the proposed product corresponds to $\alpha$-pinene epoxide. Figure 5 shows the ${ }^{1} \mathrm{H}$ NMR of the purified product after the epoxidation of $\alpha$-pinene with PAA produced in situ. The formation of the epoxide is demonstrated by the absence of the signal from the vinyl proton at $5.25 \mathrm{ppm}$, and the presence of the signal at $3.05 \mathrm{ppm}$ belonging to the proton at the epoxide ring. This chemical shift is observed due to the lower deshielding effect produced by the oxirane ring compared to the double bond in the starting

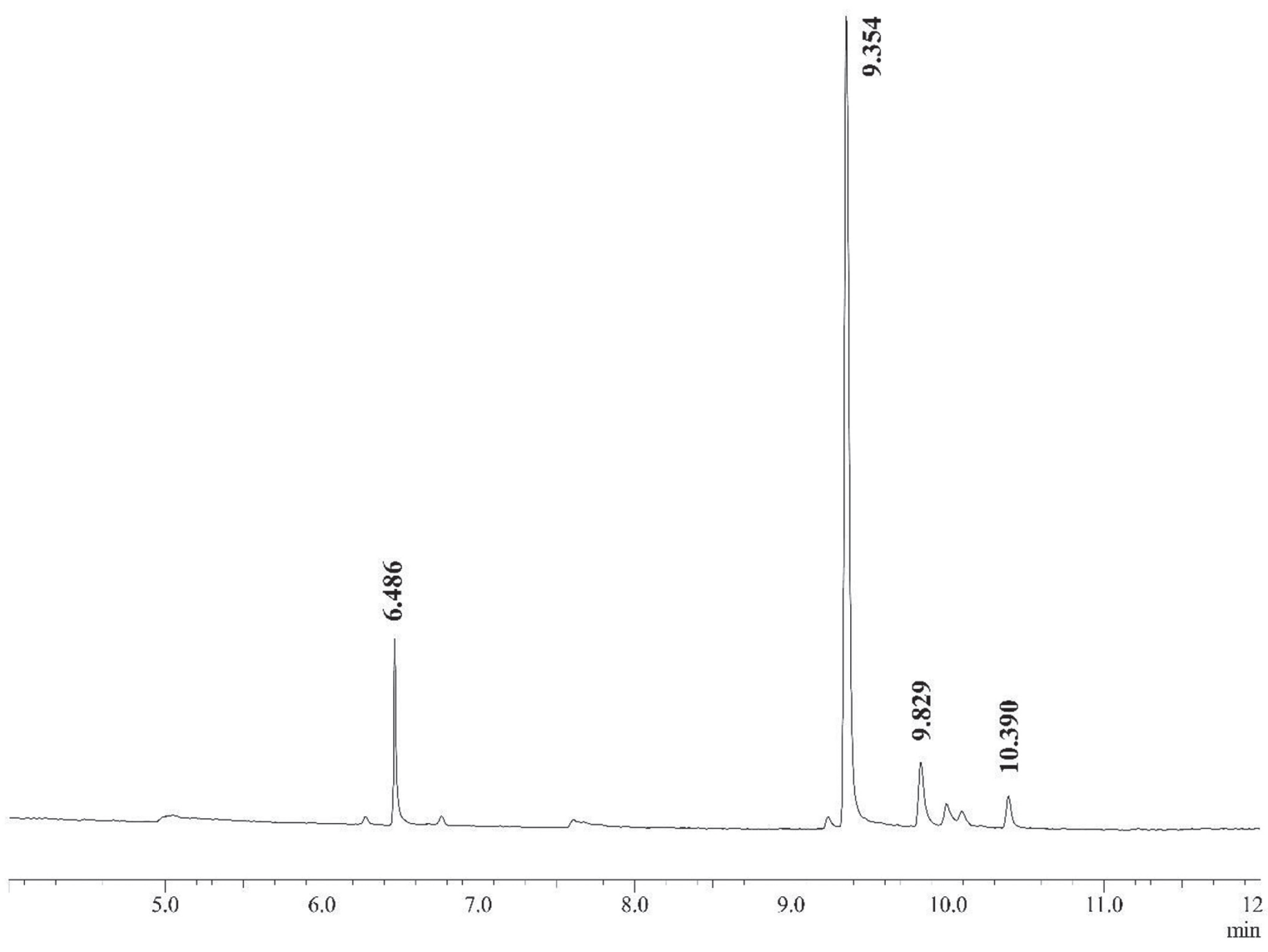

Figure 2. Chromatographic profile of the epoxidation of $\alpha$-pinene with SPC and TAED. 


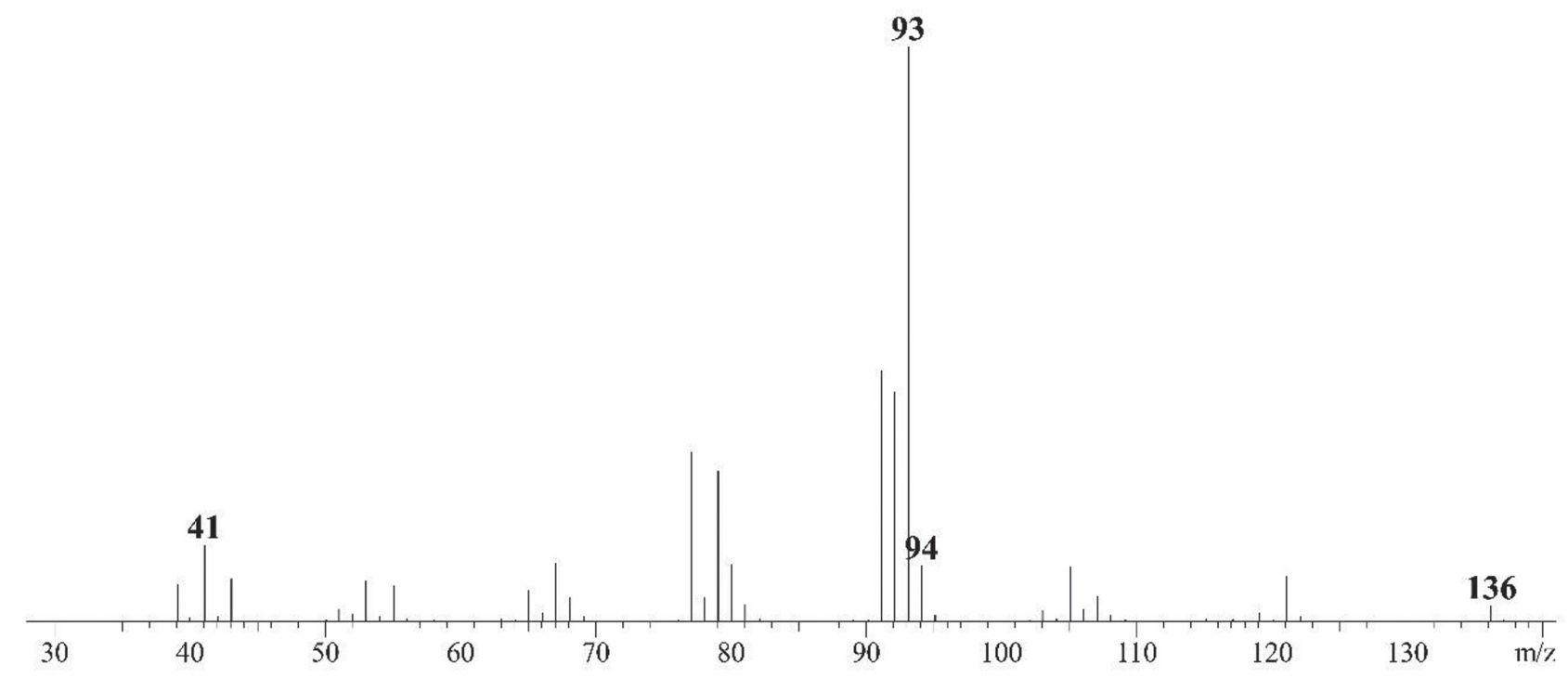

Figure 3. Mass spectrum of $\alpha$-pinene corresponding to the chromatographic peak at $6.49 \mathrm{~min}$.

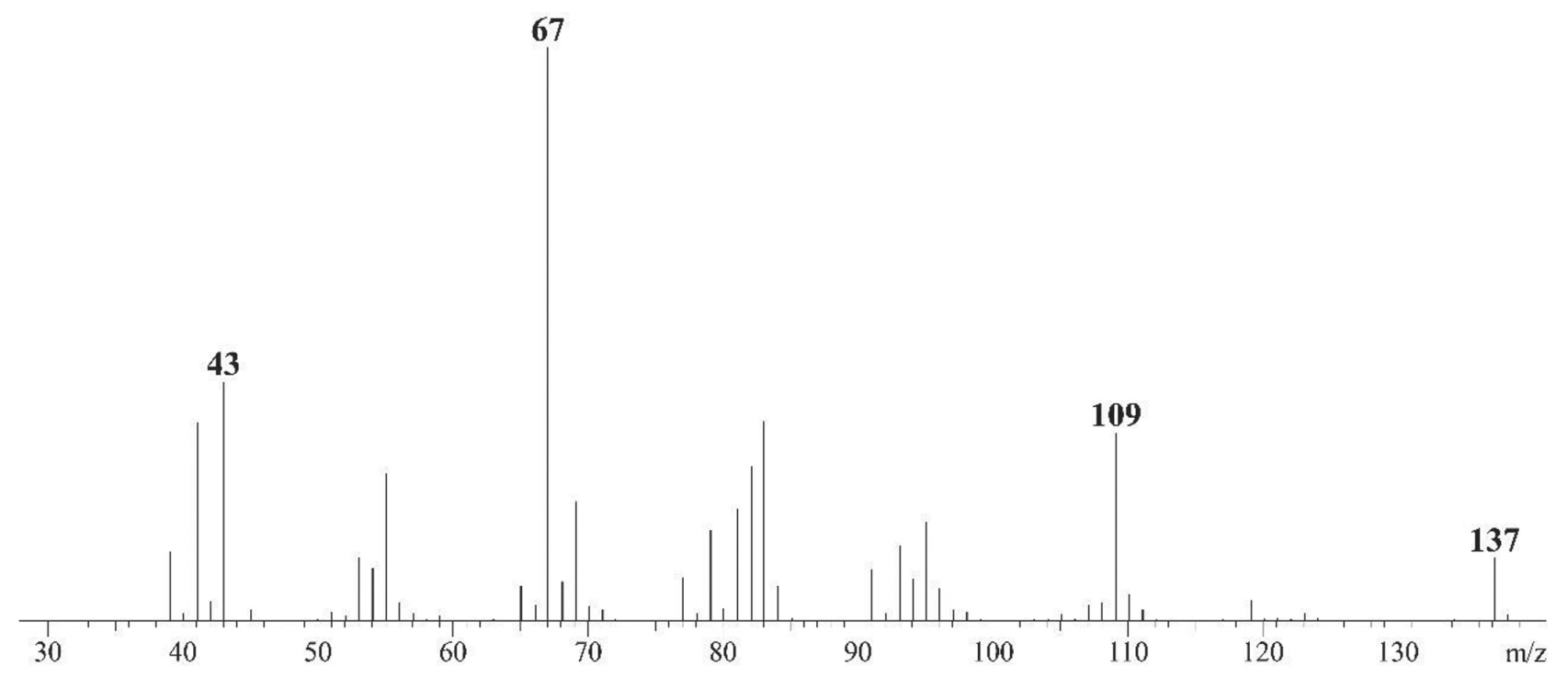

Figure 4. Mass spectrum of $\alpha$-pinene epoxide corresponding to the chromatographic peak at $9.35 \mathrm{~min}$.

material. Figure 6 shows the ${ }^{13} \mathrm{C}$ NMR spectrum of the epoxide product, which does not show any signal at low field corresponding to the double bond, 116 and $144 \mathrm{ppm}$, respectively, instead the carbons forming the oxirane ring show two signals at 57 and 60 ppm suggesting completion of the epoxidation (Figures 5 and 6 show portions of the spectra, while Figures S3 and S4 (SI section) show the full spectra with no traces of unsaturation).

All spectroscopic characterization of the product of $\alpha$-pinene epoxidation showed that the proposed reaction was successful, yielding $75 \%$ pure product. The same reaction conditions were applied to a series of monoterpenes as shown in Table 1 . While $\beta$-pinene produced the respective epoxide in 73\% yield, the model olefin, cyclohexene (3) produced the cyclohexene epoxide in $68 \%$ yield. In addition to the monoterpenes with one double bond, the series of monoterpenes containing two olefin moieties, limonene (4), $\alpha$-terpinene (5), and $(R)$-carvone (6), were also exposed to the same reaction conditions for epoxidation. Limonene showed to be regioselective for annular epoxidation, yielding $72 \%$ of cis and trans product without the presence of diepoxidation. However, since $\alpha$-terpinene contains two olefins in the monoterpene ring, epoxidation of both olefins was observed, decreasing the yield to $57 \%$, which was expected due to electronic and steric effects. Monoepoxidation was not observed, and a mixture of cis and trans $\alpha$-terpinene epoxides was obtained; the spectroscopic data are presented in the SI section. In order to understand the behavior of the inside and outside of the ring epoxidation for monoterpenes, $(R)$-carvone (6) 

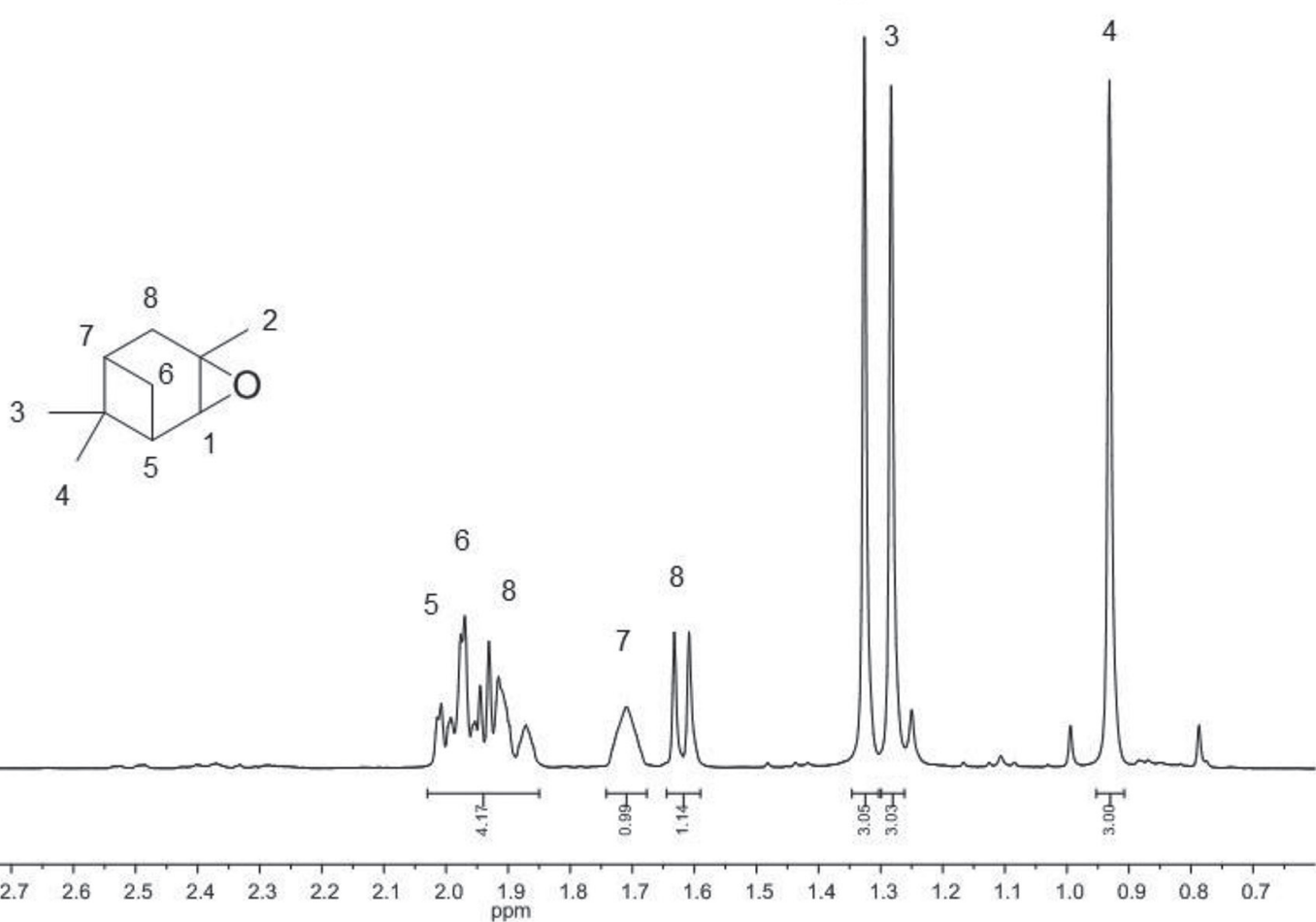

Figure 5. Expanded ${ }^{1} \mathrm{H} \mathrm{NMR}\left(400 \mathrm{MHz}, \mathrm{CDCl}_{3}\right)$ of $\alpha$-pinene epoxide.

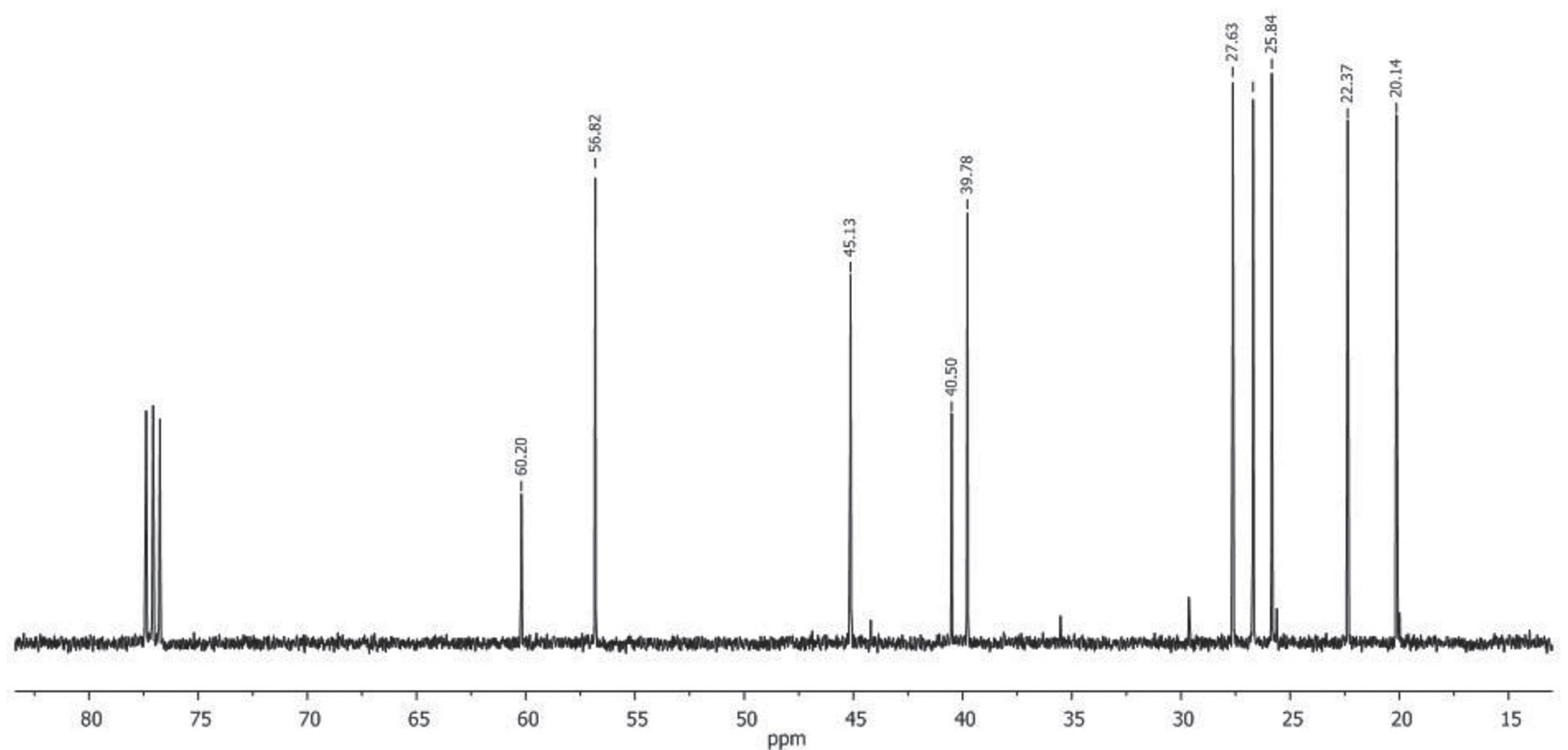

Figure 6. Expanded ${ }^{13} \mathrm{C} \mathrm{NMR}\left(100 \mathrm{MHz}, \mathrm{CDCl}_{3}\right)$ of $\alpha$-pinene epoxide.

was studied. Epoxidation of $\mathbf{6}$ under the same reaction conditions yielded only $20 \%$ of product. Epoxidation of the olefin outside of the ring was not observed, which demonstrates that the reaction was indeed regioselective for the annular olefin. However, the epoxidation occurred at a low extent due to the presence of the carbonyl group, an electron withdrawing group that shifts electron density away from the olefin. Spectroscopic characterization of the $(R)$-carvone epoxide is presented in the SI section. Since the presence of electron withdrawing groups affects the reaction, epoxidation of dibenzylidenacetone (7) and cinnamic acid (8) was performed. While in both cases epoxidation of the olefins was not observed, the cinnamic acid produced benzaldehyde and benzoic acid as undesired 
products. In general, it was observed that olefins attached to electron donating groups yielded a larger extent of epoxide product, which was the case of olefins attached to alkyl groups, 1, 2, 4, and their respective products, $\mathbf{P 1}$, $\mathbf{P 2}$, and $\mathbf{P 4}$. On the other hand, olefins attached to electron withdrawing groups, $\mathbf{6}, \mathbf{7}$, and $\mathbf{8}$, led to formation of byproducts or epoxides $\mathbf{P 6}$ in low yields. ${ }^{24}$

\section{Conclusions}

Successful synthesis of monoterpene epoxides by in situ production of peroxyacetic acid from sodium percarbonate and tetraacetylethylenediamine is reported, employing easy to access chemicals commonly used for disinfection processes. This methodology produces the desired epoxide without the use of catalysts in high yields, up to $75 \%$ depending of the monoterpene, without the need for excess peroxyacids, which are difficult to handle and expensive chemicals. The epoxidation reaction was found to be regioselective to the double bond in the ring, which was demonstrated by the annular epoxidation of limonene. The presence of electron withdrawing groups affected the formation of the desired epoxide, reducing the nucleophilic ability of the olefin to produce the oxirane ring. Additionally, this methodology is carried out at room temperature using a biphasic medium of dichloromethane and water that facilitates the final extraction of the product. These factors make this synthesis more environmentally friendly in comparison to reports using, for example: dimetyldioxirane, ${ }^{25}$ peroxyacids, ${ }^{6-8}$ tungstate ${ }^{26,27}$ and alumina. ${ }^{24}$ Other substrates are currently under study in order to expand the scope of these reaction conditions.

\section{Supplementary Information}

Supplementary data are available free of charge at http://jbcs.sbq.org.br as PDF file.

\section{Acknowledgments}

The authors express gratitude to Universidad del Cauca and Universidad Icesi for providing logistics and equipment for the development of this project.

\section{References}

1. Blanch, G. P.; Nicholson, G. J.; J. Chromatogr. Sci. 1998, 36, 37.

2. Matsubara, S.; Naumann, M.; Martin, R.; Nichol, C.; Rascher, U.; Morosinotto, T.; Bassi, R.; Osmond, B.; Exp. Bot. 2004, 56, 461.

3. Förster, B.; Pogson, B. J.; Osmond, C. B.; Plant Physiol. 2011, 111.
4. Bauer, K.; Garbe, D.; Surburg, H.; Common Fragrance and Flavor Materials: Preparation, Properties, and Uses, $3^{\text {rd }}$ ed.; Wiley-VCH: Weinheim, 2001.

5. Breitmaier, E.; Terpenes: Flavors, Fragrances, Pharmaca, Pheromones; Wiley-VCH: Weinheim, 2006.

6. Smith, M.; Organic Synthesis, $3^{\text {rd }}$ ed.; Academic Press: New York, 2011.

7. González, L. M.; Gelbard, G.; de Correa, C. M.; Rev. Fac. Ing., Univ. Antioquia 2003, 30, 61.

8. Smith, M. B.; March, J.; March's Advanced Organic Chemistry: Reactions, Mechanisms, and Structure, $5^{\text {th }}$ ed.; John Wiley \& Sons: New York, 2005.

9. Arbusow, B.; Ber. Dtsch. Chem. Ges. (A B Ser.) 1935, 68, 1430.

10. Li, A.-H.; Dai, L.-X.; Aggarwal, V. K.; Chem. Rev. 1997, 97 , 2341.

11. Besse, P.; Veschambre, H.; Tetrahedron 1994, 50, 8885.

12. Abdi, S. H. R.; Kureshy, R. I.; Khan, N. H.; Jasra, R. V.; Catal. Surv. Asia 2004, 8, 187.

13. Yang, J. Y.; Nocera, D. G.; J. Am. Chem. Soc. 2007, 129, 8192.

14. Corma, A.; Domínguez, I.; Doménech, A.; Fornés, V.; GómezGarcía, C. J.; Ródenas, T.; Sabater, M. J.; J. Catal. 2009, 265, 238.

15. Sabater, M. J.; Corma, A.; Domenech, A.; Fornés, V.; García, H.; Chem. Commun. 1997, 14, 1285.

16. Van der Waal, J. C.; Rigutto, M. S.; Van Bekkum, H.; Appl. Catal., A 1998, 167, 331.

17. Adam, W.; Corma, A.; Reddy, T. I.; Renz, M.; J. Org. Chem. 1997, 62, 3631.

18. Vartzouma, C.; Evaggellou, E.; Sanakis, Y.; Hadjiliadis, N.; Louloudi, M.; J. Mol. Catal. A: Chem. 2007, 263, 77.

19. Geller, T.; Gerlach, A.; Krüger, C. M.; Militzer, H.-C.; J. Mol. Catal. A: Chem. 2006, 251, 71.

20. Furniss, B. S.; Hannaford, A. J.; Smith, P. W. G.; Tatchell, A. R.; Vogel's Textbook of Practical Organic Chemistry, $5^{\text {th }}$ ed.; John Wiley \& Sons: New York, 1989, p. 1135.

21. Naipawer, R. E.; US pat. 4,696,766 1986.

22. Zajac Jr., W. W.; Walters, T. R.; Woods, J. M.; Synthesis 1988, 10,808 .

23. Sundberg, R. J.; Carey, F. A.; Advanced Organic Chemistry. Part B: Reactions and Synthesis, $4^{\text {th }}$ ed.; Kluwer Academic: New York, 2001.

24. Veloza, L. A.; Orozco, L. M.; Sepúlveda-Arias, J. C.; Nat. Prod. Commun. 2011, 6, 925.

25. Li, J.; Gao, S.; Li, M.; Zhang, R.; Xi, Z.; J. Mol. Catal. A: Chem. 2004, 218, 247.

26. Uguina, M. A.; Delgado, J. A.; Rodríguez, A.; Carretero, J.; Gómez-Díaz, D.; J. Mol. Catal. A: Chem. 2006, 256, 208.

27. Swern, D.; J. Am. Chem. Soc. 1947, 69, 1692.

Submitted: July 4, 2019

Published online: October 30, 2019 